\title{
Sporadic and radiation-associated papillary thyroid cancers can be distinguished using routine immunohistochemistry
}

\author{
CARSTEN BOLTZE ${ }^{1,2,5}$, ARMIN RIECKE ${ }^{3}$, CHRISTIAN G. RUF ${ }^{3}$, MATTHIAS PORT $^{4}$, HORST NIZZE ${ }^{1}$, \\ CAROLA KÜGLER $^{5}$, CLAUDIA MIETHKE ${ }^{5}$, NADINE WIEST ${ }^{5}$ and MICHAEL ABEND ${ }^{3}$ \\ ${ }^{1}$ Department of Pathology, University of Rostock; ${ }^{2}$ Department of Pathology, SRH Clinic Gera; \\ ${ }^{3}$ Bundeswehr Institute of Radiobiology, German Armed Forces, Munich; ${ }^{4}$ Department of Hematology, \\ Hemostasis and Oncology, Hannover Medical School, Hannover; ${ }^{5}$ Department of Pathology, \\ Otto-von-Guericke-University Magdeburg, Germany
}

Received January 29, 2009; Accepted March 24, 2009

DOI: $10.3892 /$ or_00000457

\begin{abstract}
We investigated protein abundance in order to differentiate radiation-associated papillary thyroid cancers (PTC) from other etiologies for e.g. forensic purposes. Proteins were extracted from frozen tissues originating from 91 sporadic PTCs and 86 post-Chernobyl PTCs. Proteins were separated gel-electrophoretically, gels were silver stained, spots scanned and their intensity quantified. After excision of spots from the gel and protein digestion, MALDITOF mass spectrometry was performed followed by correlation of these results to human proteins using appropriate software and database. After this screening approach, altogether 20 candidate proteins were selected and measured semiquantitatively (Remmele score) using immunohistochemistry. Logistic regression modeling was performed for discriminating the groups. NTRK1, metalloproteinases (MMP-1, MMP-9 and MMP-13) and Cathepsins (-W and -X) proved to be of highest significance for discriminating the groups irrespective of the regression model utilized. When considering age and gender, each of 3 proteins by itself made possible a complete separation of the groups otherwise a combination of 2 of the 5 proteins mentioned was needed. In conclusion, abundance of proteins known to be associated with a more aggressive tumor type (MMPs and Cathepsins) appeared increased in post-Chernobyl PTC compared to sporadic PTC, thus underlining the known aggressiveness of radiation-associated PTC. These proteins make it possible to completely distinguish post-Chernobyl from sporadic PTC using routine immunohistology.
\end{abstract}

Correspondence to: Dr Armin Riecke, Bundeswehr Institute of Radiobiology, German Armed Forces, Neuherbergstr. 11, 80937 Munich, Germany

E-mail: michaelabend@bundeswehr.org

Key words: proteomics, papillary thyroid cancer, radiation

\section{Introduction}

Radiation exposure at a young age is an environmental factor known to cause thyroid cancer, predominantly of the papillary type $(1,2)$. The risk of thyroid tumors increases linearly for mean doses as low as $100 \mathrm{mGy}$ (3). As a result of the Chernobyl nuclear reactor accident (April 1986), an enormous increase (approximately 30-fold, especially in the age group of $<1$ year at exposure, for details see ref. 4) in the incidence of childhood thyroid carcinoma has been observed in Belarus, Ukraine, and, to a lesser extent, in the Russian Federation starting in 1990 (5). In comparison to sporadic thyroid cancer, the post-Chernobyl carcinomas adumbrate a different clinical behavior. A comparison of the childhood thyroid cancer from Belarus with a non-exposed group of the same age from Japan showed a high percentage of extra-thyroidal spread in the Belarus cohort, though the mean tumor diameter was smaller than in the Japanese group. The incidence of solid growth pattern as a sufficient criterion for poorly differentiated tumors was also higher in the Belarusian cases than in the unexposed Japanese group, indicating a more aggressive potential of the Belarusian cases (6). RET activation/ rearrangements were found in nearly $70 \%$ of the patients (5).

However, the exact impact of the Chernobyl accident on thyroidal cancer development in the Ukraine and Europe was difficult to define. For example, between 1980 and 2000 cancer of the thyroid significantly increased in France (7). Epidemiological evidence did not suggest a link with the Chernobyl accident, but the Thyroid Cancer Committee recommended a national registry dedicated to thyroid cancer in young people (7). Similar findings of an increasing incidence of thyroid cancer years after the Chernobyl accident are reported from Belgium and England (2 and 8). Even in Belarus there was a debate on whether the reported increase of thyroid cancer is real and attributable to radiation or rather an artifact due to incorrect histological diagnosis, more complete case reporting, and mass screening of children after the accident (9).

These uncertainties, together with epidemiological reasons (improved risk assessment due to a more specific bioindicator of radiation exposure), forensic purposes or potential compensation claims, have tempted scientists to 
examine biological parameters for radiation-associated thyroid cancer. It was the focus of our study to compare the same histology, which developed due to a different etiology. For this reason, proteins from tumor tissue of Belarusian patients subjected to radiation after the Chernobyl nuclear accident and proteins from a control group were compared by combining 2-D gel electrophoresis with MALDI-TOF mass spectrometry. After this screening approach, candidate proteins were semi-quantitatively measured (Remmele score) on histological slides using immunohistochemistry. This was performed in order to develop an easy to handle test for distinguishing between sporadic and radiation-associated papillary thyroid cancer (PTC) on histological slides.

\section{Materials and methods}

Tumor samples. We examined thyroid cancers from 86 patients (46 females and 40 males) diagnosed up to 15 years after external and internal radiation exposure due to the Chernobyl nuclear accident (Table I). Mean age at exposure was 11.8 years (standard deviation 4.5 years, range 3-23 years, Table I). Patients were located within a $10-50 \mathrm{~km}$ distance from the reactor during the catastrophe $48 \mathrm{~h}$ after the accident the population living in a proximity of about $20 \mathrm{~km}$ was evacuated. Within that time the absorbed intrathyroidal dose was estimated to amount to $0.15-1.0 \mathrm{~Gy}$ for $90 \%, 1-5 \mathrm{~Gy}$ for $9 \%$ and $>10$ Gy for $1 \%$ of the evacuated children (10). After total thyroidectomy due to advanced carcinoma, thyroid tumor samples of the tumor tissue were taken and stored at $-80^{\circ} \mathrm{C}$. Mean age at operation was 18.6 years (standard deviation 4.0 years, range $12-28$ years, Table I) due to a mean latency period of 6.8 years.

Cryopreserved tumor tissues from 91 Caucasian patients (42 females and 49 males) of southeastern Germany suffering from thyroidal carcinoma of similar histology but lacking a radiation exposure history served as controls. Mean age was 50.1 years (standard deviation 16.7 years, range $15-83$ years, Table I). The tumors were histologically analyzed by two pathologists according to WHO classification. Only papillary thyroid histologies and no follicular subtypes were included in this study. Tumor stage was based on the TNM tumor classification system (11). The studies were approved by the local ethics committees of Otto-von-Guericke-University, Magdeburg and all patients gave their written consent.

Protein extraction. From all biopsies frozen tissue pieces of about $200 \mathrm{mg}$ each were placed into a mortar in liquid nitrogen. Using a chilled pestle, the frozen tissue was crushed to fine powder. This powder was weighed and kept at $-80^{\circ} \mathrm{C}$ for further work-up. Rehydration buffer ( $8 \mathrm{M}$ urea, $2 \% \mathrm{CHAPS}$, $0.5 \%$ IPG buffer, $16 \mathrm{mM}$ DTT), complete protease inhibitor cocktail with EDTA (Roche), and PMSF/pepstatin A were added for extraction of proteins. Predetermined volumes were added frozen to the tissue powder, ground and left on ice to become solvent. Afterwards, the solution was vortexed for $30 \mathrm{sec}$. The mixture was put on ice again for $1 \mathrm{~min}$, vortexed again for $30 \mathrm{sec}$, and finally snap-frozen in liquid nitrogen. In the next step, the mixture consisting of buffer and tissue was thawed to $4^{\circ} \mathrm{C}$ by vortexing and centrifugation for $10 \mathrm{~min}$ at $13.000 \mathrm{x} \mathrm{g}$ in a refrigerated microfuge. The pellets containing insoluble materials were discarded and the supernatants were transferred to a labeled polypropylene tube and stored at $-80^{\circ} \mathrm{C}$ for further use. Protein concentration was measured from each individual vial using a commercial protein determination assay (2-D Quant kit, Amersham Biosciences).

2-DE and image analysis. Isoelectric focusing (IEF) was carried out on an IPGphor (Amersham Biosciences) using precast $18 \mathrm{~cm} \mathrm{pH} \mathrm{3.0-10.0} \mathrm{linear} \mathrm{IPG} \mathrm{gel} \mathrm{strips.} \mathrm{Total} \mathrm{protein}$ $(350 \mu \mathrm{g})$ for analytical runs was mixed with a rehydration solution containing $8 \mathrm{M}$ urea, $2 \%$ CHAPS, $0.5 \%$ IPG buffer (pH 3.0-10.0), $20 \mathrm{mM}$ DTT, and a trace of bromophenol blue, to a total volume of $400 \mu 1$. Rehydration and IEF were performed as follows: $6 \mathrm{~h}$ rehydration with no voltage applied, IEF at $30 \mathrm{~V}$ for $6 \mathrm{~h}, 500 \mathrm{~V}$ for $1 \mathrm{~h}, 1000 \mathrm{~V}$ for $1 \mathrm{~h}$ and $8000 \mathrm{~V}$ for $4 \mathrm{~h}$. Current intensity was limited to $50 \mu \mathrm{A}$ per gel strip. After IEF separation, the gel strips were immediately equilibrated for two steps in equilibrium buffer, including $50 \mathrm{mM}$ Tris- $\mathrm{HCl}$ (pH 8.8), $6 \mathrm{M}$ urea, $30 \%$ glycerol, and $2 \%$ SDS. In the first step, DTT $(0.5 \%)$ was included in the equilibrium buffer. Iodoacetamide $(2 \%)$ was added in the second step. The second dimension separation was performed using a Protean II xi 2-D cell (Biorad, Richmond, CA, USA) with the following procedure: $20 \mathrm{~mA}$ per gel for $40 \mathrm{~min}$ and $30 \mathrm{~mA}$ per gel until the bromophenol blue front reached the bottom of the gel (Fig. 1). All gels were scanned as 16 bit grayscale tiff-images using a Mirage II scanner (Umax Data Systems). In order to perform differential analysis, one gel image of each group was chosen as reference gel image such that it best represented the respective pool of gel images. Differential computer-based 2D-gel analysis was carried out using the software package Phoretics 2D Advanced Version 6.01 (Nonlinear Dynamics Ltd.). In cases of low spot intensities, a contrast improvement was reached by using local compensation in the software Corel Photo-Paint 11.0 for Mac. For densitometric analysis (spot detection, background subtraction, volume normalization and calculating ratios among corresponding spots), selected gels containing all protein spots of interest were compared to each other in all gels.

Sample preparation for MALDI-TOF MS. In-gel digestion of proteins from 10 representative silver stained gels per group was performed as follows: Spots were excised to $1-2 \mathrm{~mm}^{2}$ slices using a blade, destained with freshly prepared $15 \mathrm{mM}$ potassium ferricyanide $/ 50 \mathrm{mM}$ sodium thiosulfate, washed with $25 \mathrm{mM}$ ammonium bicarbonate $/ 50 \%$ acetonitrile, and dried in a SpeedVac Plus SC110A vacuum concentrator (Savant, Holbook, NY, USA). The dried gel pieces were rehydrated with 3-10 $\mu \mathrm{l}$ of $20 \mathrm{ng} / \mu \mathrm{l}$ trypsin solution, the solution volume being sufficient for the dried gel to re-swell. Digestion was continued at $37^{\circ} \mathrm{C}$ for $10-15 \mathrm{~h}$. Tryptic peptides were first extracted using 5\% TFA at $40^{\circ} \mathrm{C}$ for $1 \mathrm{~h}$, then $2.5 \%$ TFA $/ 50 \%$ acetonitrile at $30^{\circ} \mathrm{C}$ for $1 \mathrm{~h}$. The extracted solutions were mixed in an Eppendorf tube and dried in a vacuum concentrator.

MALDI-TOF MS identification of peptide mixtures. The peptide mixture was solubilized with $0.5 \%$ TFA for mass spectrometry (MS) analysis. MS was performed on a Reflex 
Table I. Characteristics of sporadic and radiation-associated PTC: age at operation and gender related differences in both groups were calculated using $\chi^{2}$ statistic (p-values are shown).

\begin{tabular}{|c|c|c|c|c|c|c|c|c|c|c|c|c|c|c|}
\hline \multirow[t]{2}{*}{ Thyroid cancer } & \multirow[b]{2}{*}{$\frac{\mathrm{N}}{\text { (total 177) }}$} & \multicolumn{3}{|c|}{ Gender } & \multicolumn{6}{|c|}{ Age at operation (years) } & \multicolumn{4}{|c|}{ Age at exposure (years) } \\
\hline & & Male & Female & $\chi^{2}$ & Mean & Median & SD & Range & $\begin{array}{c}\text { Overlap } \\
\# 1 \%\end{array}$ & $\chi^{2}$ & Mean & Median & SD & Range \\
\hline Sporadic & 91 & 49 & 42 & & 50.1 & 50.0 & 16.7 & $15-83$ & $14 / 15.4$ & & & & & \\
\hline $\begin{array}{l}\text { Radiation- } \\
\text { associated }\end{array}$ & 86 & 40 & 46 & 0.3 & 18.6 & 18.0 & 4.0 & $12-28$ & $72 / 83.7$ & $<0.0001$ & 11.8 & 11.0 & 4.5 & $3-23$ \\
\hline
\end{tabular}

Total number (\#) and percent (\%) are given for overlapping ranges in age at operation for both groups.

III MALDI-TOF mass spectrometer (Bruker Daltonics, Bremen, Germany) with saturated alpha-cyano-4-hydroxytrans-cinnamic (CHCA) solution in a $0.1 \%$ TFA/50\% acetonitrile as matrix. Mass spectra were externally calibrated with peptide standard from Bruker or internally calibrated with autodigest peaks of trypsin $\left(\mathrm{MH}^{+}\right.$: 906.5, 1020.5, 1153.6, 2163.1 and 2273.2 Da).

Database search. Database searches were performed against an in-house SWALL sequence database (SWISS-Prot and TrEMBL) using Mascot 2.01 software (Matrix Science) via BioTools 2.1 software (Bruker Daltonics). A mass tolerance of $80 \mathrm{ppm}$ and one missing cleavage site were pre-selected, oxidation of methionine residues was considered as variable modification, and carboxyamidomethylation of cysteines as fixed modification. The search was restricted to human proteins. All results were examined carefully for reliability and occurrence of multiple proteins in the same sample. Proteins were named using Swiss Prot accession numbers (Table II).

\section{Immunohistochemistry}

Immunostaining and evaluation. Cryostat sections $(5 \mu \mathrm{m})$ taken from all biopsies were mounted onto poly-L-lysinecoated slides and fixed in ice-cold methanol for $1 \mathrm{~min}$. Endogeneous peroxidase activity was inhibited using a $0.5 \%$ solution of $\mathrm{H}_{2} \mathrm{O}_{2}$ in $\mathrm{pH} 7.5 \mathrm{PBS}$ for $2 \mathrm{~min}$. Normal horse serum diluted 1:20 with PBS containing 1\% BSA was incubated with the samples for $20 \mathrm{~min}$ to suppress nonspecific binding. Tissue sections were incubated with monoclonal or polyclonal primary antibodies against all 20 proteins according to the manufacturer's recommendations at a 1:100 or $1: 200$ dilutions for $60 \mathrm{~min}$ at $37^{\circ} \mathrm{C}$ (Table II). After washing in PBS, the samples were incubated with a 1:1000 dilution of biotinylated goat anti-mouse secondary antibody for $20 \mathrm{~min}$. The signal was detected using the streptavidin-biotin-peroxidase complex method (LSAB). DAB (3,3'-diaminobenzidine hydrochloride containing $0.08 \%$ hydrogen peroxide) was used as a chromogen to visualize the peroxidase activity. Finally, the sections were counterstained with hematoxylin.

Specificity of immunostaining was checked by omitting single steps in the immunochemical protocol and by replacing primary antibody with non-immune serum. Tissue from a xenotransplant of a dedifferentiated thyroid carcinoma was used as a positive control. Three sections of each tissue were immunohistochemically examined by two independent reviewers. In 10 high power fields of each section, positive stained tumor cells were counted and assessed. An immunoreactive score (IRS) was set up for all proteins, following Remmele et al (12). The level of staining intensity (SI) was subdivided into four groups: 0 (negative), 1 (weak), 2 (moderate) and 3 (strong). The percentage of positive cells (PP) was regarded as 0 (none), $1(<10 \%), 2$ (10-50\%), 3 (51$80 \%)$ and $4(>80 \%$ positive tumor cells). The product of SI and PP is the IRS (0-12). A score of 0-2 was regarded as negative or neglectably low, 3-6 as moderate and more than 6 as strong (score $>6$ was defined as positive immunoreactivity $=$ cut-off). The protein expression in stromal cells and in cells of hematopoietic origin was observed, but had no influence on the Remmele-Score.

Statistics. Logistic regression models were performed with PTC origin (radiation-associated vs. sporadic) representing the independent binary variable. Dependent variables containing either numerical (Remmele score 0-12) or categorical (positive or negative Remmele score) protein data entered the unadjusted as well as age-at-operation and gender adjusted models separately in order to select for top discriminative proteins using $\chi^{2}$ statistic. This statistic is associated with calculating the maximum likelihood estimate of the dependent variables entered as a mean for the model-fitting. Regression models and descriptive statistics were performed using statistical analysis software (SAS 9.1.3, Cary, NC, USA).

\section{Results}

Protein identification and quantification. Altogether 1,920 \pm 41 and $2,045 \pm 65$ spots were identified on the reference gels associated to sporadic and radiation-associated PTC, respectively. A strong similarity in abundance and intensity of protein spots was found within each group and also between the groups. In order to obtain a general picture of the soluble protein content in PTC tissues, a total of 165 spots were selected for mass spectrometric identification. Many of the selected protein spots contained cellular protein species of cytoskeletal origin or cytoskeletal-associated proteins, such as tropomyosins and cytokeratins. A group of enzymes included for instance alpha enolase or glyceraldehydes 3phosphate dehydrogenase. Some cell signaling proteins such 


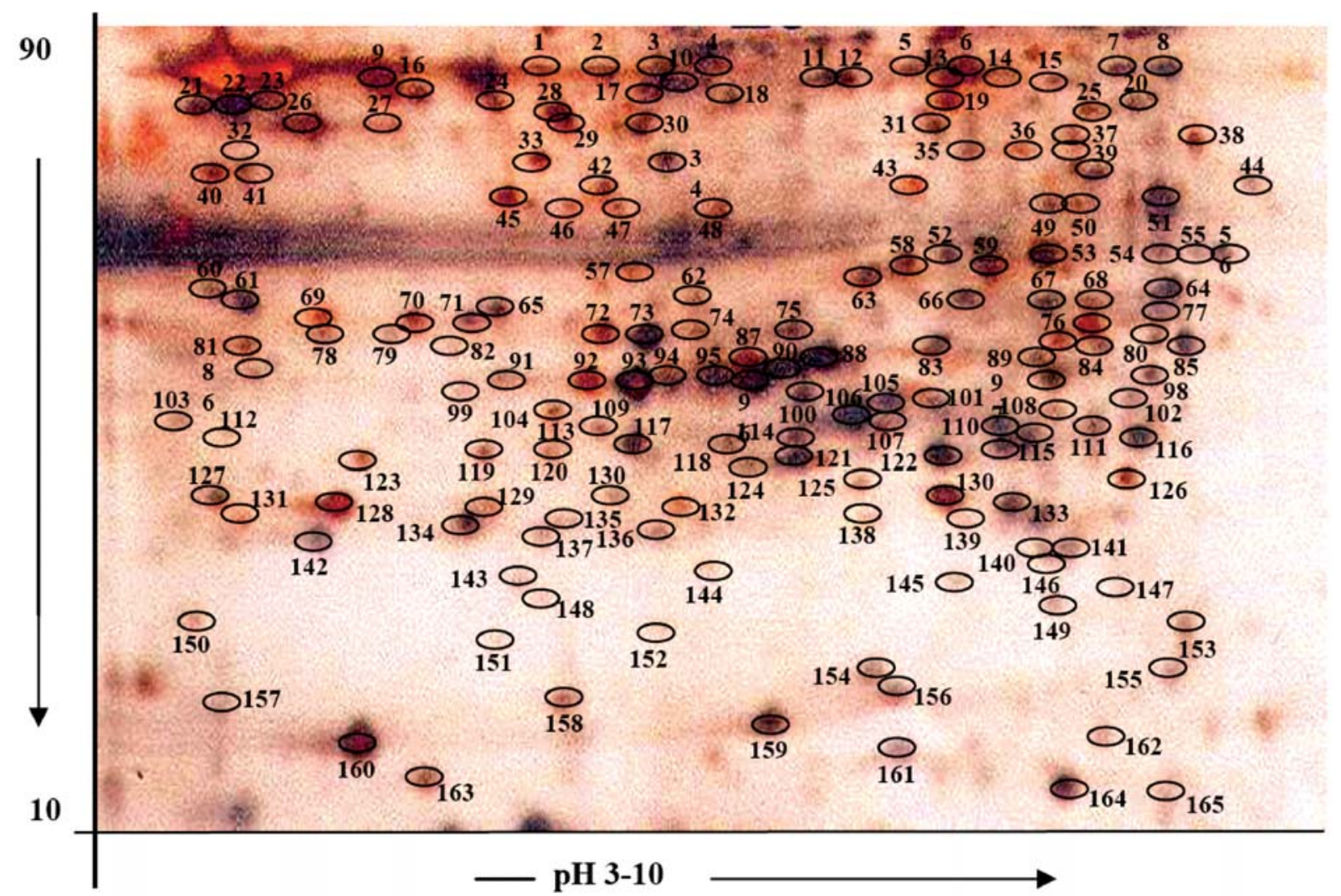

Figure 1. A representative 2-D gel-electrophoresis (isoelectric focusing in one dimension and $\mathrm{pH}$ separation in the second dimension) performed on sporadic PTC enabled the detection of 165 reproducible spots found in higher abundance in all gels containing protein extracts from radiation-associated PTC. These spots were selected for mass spectrometric analysis and then, based on these results, identified by a database search.

Table II. Based on mass spectrometric analysis of proteins selected by 2-D gel electrophoresis (Fig. 1), a data base search (Swiss-Prot) allowed identification of protein names.

\begin{tabular}{|c|c|c|c|c|}
\hline $\begin{array}{l}\text { Spot } \\
\text { no. }\end{array}$ & Swiss-Prot & Proteine name & $\begin{array}{l}\text { Densitometric } \\
\text { values }\end{array}$ & $\begin{array}{c}\text { Antibody/companies } \\
\text { name }\end{array}$ \\
\hline 6 & P30530 & Tyrosine-protein kinase receptor Axl & 40.6 & $\mathrm{mc} / \mathrm{abo}$ \\
\hline 7 & Q13635 & Patched protein PTCH (splice) & 81.6 & $\mathrm{pc} / \mathrm{abo}$ \\
\hline 8 & P04629 & Nerve growth factor receptor NTRK1 & 65.3 & pc/abo \\
\hline 10 & Q02156 & Protein kinase $\mathrm{C}$ epsilon & 113.3 & pc/abo \\
\hline 13 & Q14393 & growth arrest-specific gene (gas6) & 30.9 & $\mathrm{pc} / \mathrm{sc}$ \\
\hline 14 & P14780 & MMP-9 & 49.3 & $\mathrm{mc} / \mathrm{abo}$ \\
\hline 15 & P51511 & MT2-MMP & 35.3 & $\mathrm{mc} / \mathrm{abo}$ \\
\hline 25 & O95394 & Phosphoacetylglucosamine mutase & 22.9 & $\mathrm{pc} / \mathrm{sc}$ \\
\hline 51 & P45452 & MMP-13 & 56.3 & $\mathrm{mc} / \mathrm{abo}$ \\
\hline 87 & P36952 & Maspin & 23.3 & $\mathrm{mc} / \mathrm{abo}$ \\
\hline 88 & P56202 & Cathepsin W & 34.5 & $\mathrm{mc} / \mathrm{abo}$ \\
\hline 117 & P04792 & HSP27 & 28.3 & $\mathrm{mc} / \mathrm{abo}$ \\
\hline 128 & Q9UBR2 & Cathepsin X & 44.4 & $\mathrm{pc} / \mathrm{rd}$ \\
\hline 136 & P62993 & Growth factor receptor-bound protein 2 & 23.8 & $\mathrm{mc} / \mathrm{sc}$ \\
\hline 143 & O14618 & Copper chaperone for SOD & 45.3 & pc/abo \\
\hline 150 & O75496 & Geminin & 65.8 & $\mathrm{mc} / \mathrm{sc}$ \\
\hline 160 & P06702 & Calgranulin B & 24.1 & $\mathrm{mc} / \mathrm{sc}$ \\
\hline 164 & Q66MN3 & Opticin & 18.9 & $\mathrm{mc} / \mathrm{ls}$ \\
\hline
\end{tabular}

Depicted spot numbers correspond to the 2-D gel electrophoretic image shown in Fig. 1. Densitometric values reflect the ratio of measurements calculated between radiation-associated proteins and their sporadic counterparts. Only ratios of densitometric values with increased protein abundance in PTC are shown. Their order follows the increasing spot number shown in Fig. 1. Employed primary monoclonal (mc) and polyclonal (pc) antibodies/company names (abo, antibodies-online.com; sc, SantaCruz Biotechnology; rd, R\&D Systems; 1s, Lifespan Biosciences) for immunohistochemistry are provided in the last column. 


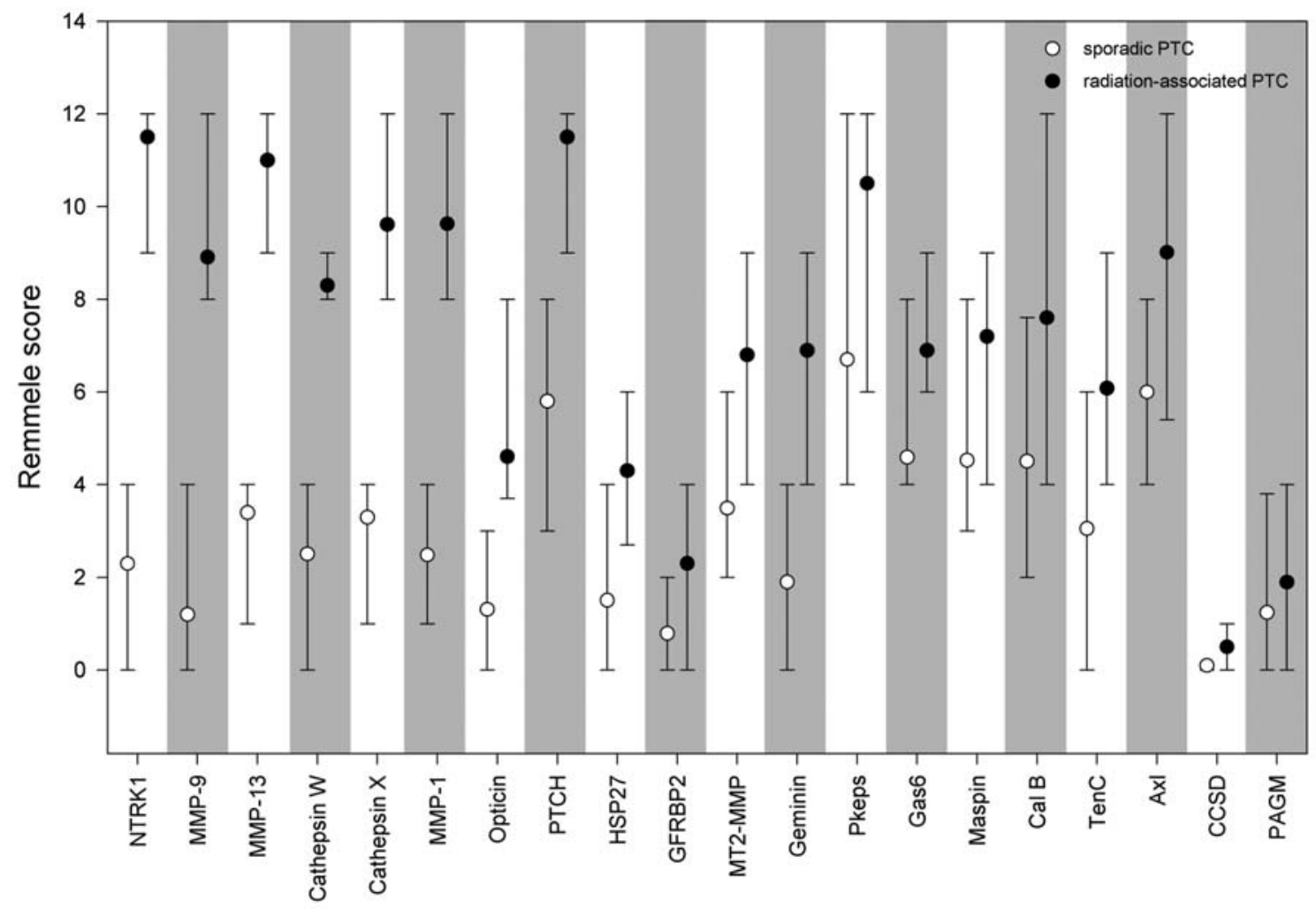

Figure 2. Immunohistochemical results of 20 proteins performed on histological slides of each PTC were converted into numerical Remmele scores. The sequence in which they are depicted correlates with the proteins' significance for discriminating both groups. Symbols represent mean values, error bars the 10 th and 90 th percentile.

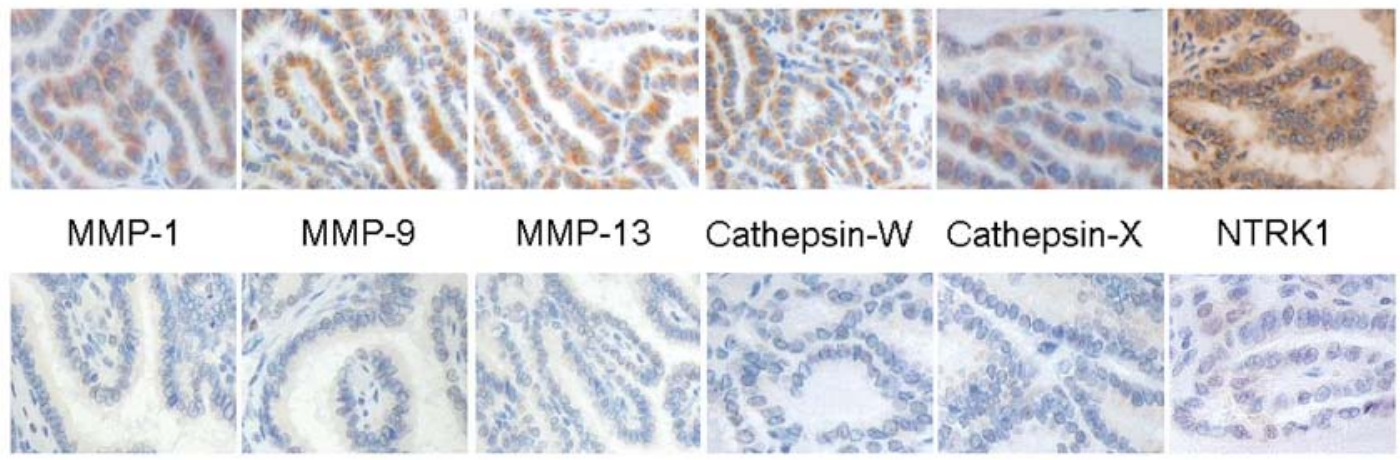

PTC radiationassociated

sporadic

Figure 3. Representative immunohistochemical results are depicted for the 6 proteins with the highest significance for discriminating radiation-associated PTC from sporadic PTC.

as vimentin were also identified. In addition, prominent spots representing species of high abundance in plasma were identified in all gels, such as serum albumin and apolipoprotein. Also, blood cell-derived proteins such as tubulin beta, hemoglobin alpha and beta were found.

In order to exclude interindividual differences, all protein spot abundance differences that were picked up in the reference gel images needed to be confirmed in all other gels from the respective pools. Only the differences that remained were considered to be radiation-associated. Using such stringent selection criteria, clear intensity differences between sporadic and radiation-associated PTC with upregulated proteins were found in only 18 spots (Table II).

Immunohistochemistry. Immunohistochemical results of 20 proteins performed on histological slides of each PTC were converted into numerical Remmele scores and brought into a sequence according to their significance for discriminating the groups (Fig. 2 and column 1 of Table III). These 20 proteins consisted of 18 proteins selected from our proteomic approach. Two additional proteins were added to this approach, since gene expression analysis performed on 
Table III. Twenty proteins were arranged according to their significance for discriminating radiation-associated from sporadic PTC.

\begin{tabular}{|c|c|c|c|c|c|}
\hline \multirow[b]{3}{*}{ Protein } & \multicolumn{5}{|c|}{ Remmele score and associated p-values $\left(\chi^{2}\right)$} \\
\hline & \multicolumn{2}{|c|}{ Age (at operation) and geder adjusted } & \multicolumn{3}{|c|}{ Unadjusted } \\
\hline & Continous score & $\begin{array}{l}\text { Categorical score } \\
\quad(\text { cut off } \leq 6)\end{array}$ & $\begin{array}{l}\text { Categorical score } \\
\quad(\text { cut off } \leq 6)\end{array}$ & $\begin{array}{c}\text { False } \\
\text { positive } \\
\mathrm{n}(\%)\end{array}$ & $\begin{array}{c}\text { False } \\
\text { negative } \\
\text { n }(\%)\end{array}$ \\
\hline NTRK1 & Complete separation & Complete separation & Complete separation & $0(0)$ & $0(0)$ \\
\hline MMP-1 & Complete separation & Complete separation & Quasi complete separation & $0(0)$ & $1(0.6)$ \\
\hline MMP-13 & Complete separation & Complete separation & Quasi complete separation & $0(0)$ & $1(0.6)$ \\
\hline MMP-9 & Complete separation & Quasi complete separation & Quasi complete separation & $0(0)$ & $3(1.7)$ \\
\hline Cathepsin W & Complete separation & Quasi complete separation & Quasi complete separation & $0(0)$ & $7(4.0)$ \\
\hline Cathepsin X & Complete separation & Quasi complete separation & Quasi complete separation & $0(0)$ & $2(1.1)$ \\
\hline Opticin & Complete separation & ND & ND & & \\
\hline PTCH & Quasi complete separation & 0.004 & $<0.0001$ & & \\
\hline Geminin & 0.002 & ND & ND & & \\
\hline MT2-MMP & 0.002 & 0.315 & $<0.0001$ & & \\
\hline Pkeps & 0.003 & 0.001 & $<0.0001$ & & \\
\hline Gas6 & 0.003 & 0.057 & 0.0002 & & \\
\hline Maspin & 0.004 & 0.050 & $<0.0001$ & & \\
\hline Cal B & 0.004 & 0.063 & $<0.0001$ & & \\
\hline TenC & 0.011 & 0.385 & 0.003 & & \\
\hline Axl & 0.011 & 0.012 & $<0.0001$ & & \\
\hline HSP27 & 0.001 & ND & ND & & \\
\hline GFRBP2 & 0.002 & ND & ND & & \\
\hline CCSD & 0.100 & ND & ND & & \\
\hline PAGM & 0.331 & ND & ND & & \\
\hline
\end{tabular}

\section{Combinations}

MMP-1 + MMP-9 Complete separation

MMP-1 + MMP-13 Complete separation

MMP-9 + MMP-13 Complete separation

Cathepsin-W +-X Complete separation complete separation

complete separation

complete separation

complete separation

$\begin{array}{lll}\text { complete separation } & 0(0) & 0(0) \\ \text { complete separation } & 0(0) & 0(0) \\ \text { complete separation } & 0(0) & 0(0) \\ \text { complete separation } & 0(0) & 0(0)\end{array}$

Significance was analyzed using different logistic regression models. This arrangement order followed the $\chi^{2}$ statistic (p-value) associated with maximum likelihood estimates of variables containing either continuos or categorical Remmele scores. Sequence of proteins in column 1 was slightly changed according to the results received from unadjusted regression models. False positive/negative results are depicted for better judgement of statements (complete/quasi complete separation) used when computing maximum likelihood estimates in SAS.

the same groups indicated upregulation for MMP-1 in radiation-associated PTC (13) and Tenascin C was described as a special feature of PTC (14). Also, antibodies were commercially available for them.

After categorizing Remmele scores into negative and positive scores (cut off $\leq 6$ introduced) and considering gender and age at operation 6 proteins with highest significance for discriminating the groups remained (Table III). These were NTRK1, MMP-1, MMP-9, MMP-13 and Cathepsin-W as well as Cathepsin-X. Representative immunohistochemical images among the groups are shown in Fig. 3.

Without considering age at operation and gender, still NTRK1 by itself and a combination of two of these proteins proved to completely discriminate radiation-associated from sporadic PTC (Table III). Frequency of false negative results (radiation-associated PTC were not recognized) among uncombined proteins ranged between 1-7 from 177 PTC (Table III). Frequency of false positive results (radiationassociated PTC falsely identified as sporadic PTC) among uncombined proteins was always 0 (Table III).

\section{Discussion}

Accidental radiation exposures (e.g. Chernobyl nuclear power plant accident) or radiological/nuclear threats (e.g. terrorist attacks using a 'dirty bomb') are likely scenarios and potentially associated with increased tumor risk. Until now it is impossible to evaluate whether a reported increase of 


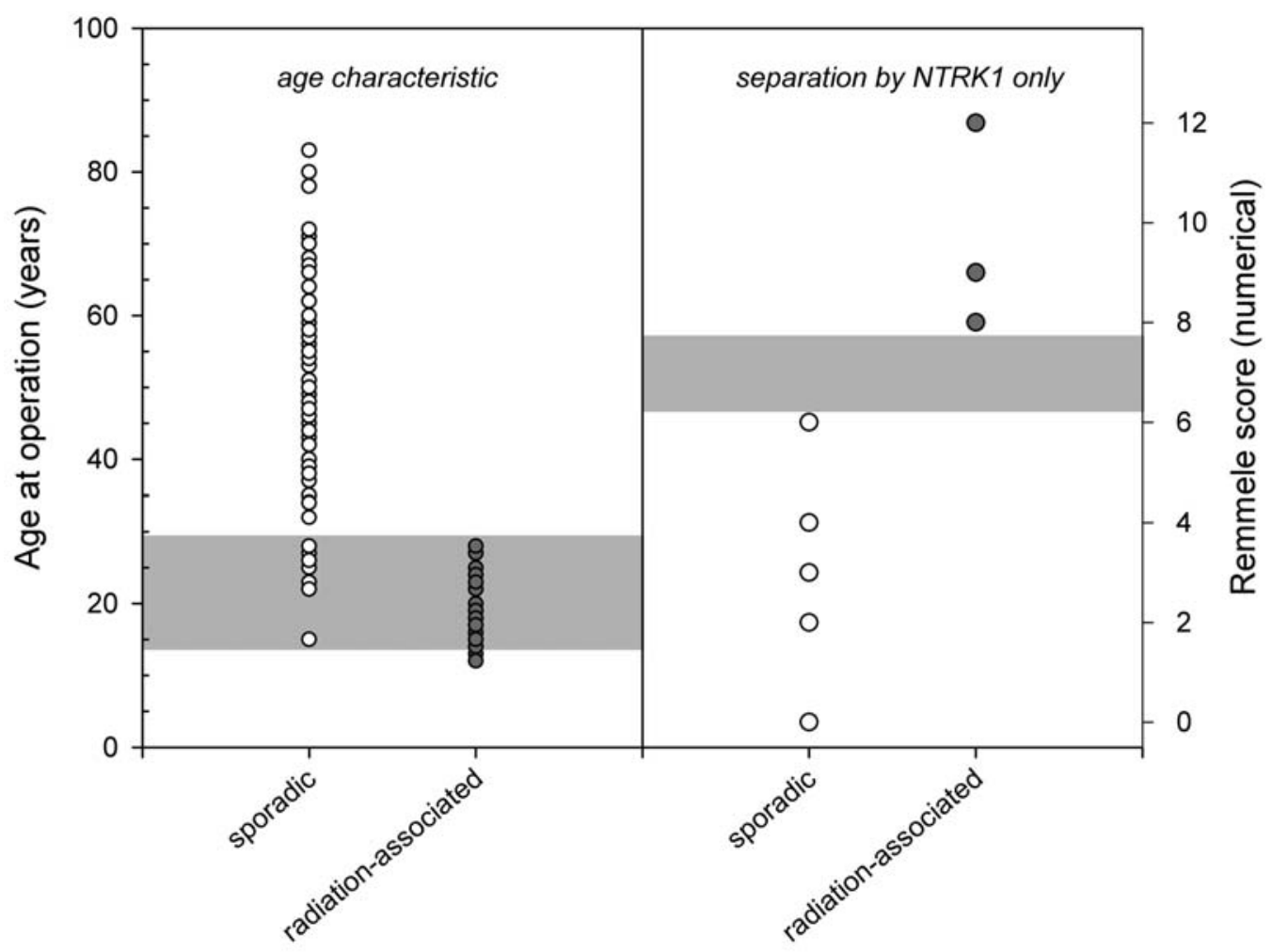

Figure 4. An overlap (gray bar) in age at operation was found for sporadic and radiation-associated PTC (left graph side) thus making the introduction of an individual biological parameter (e.g. NTRK1 protein abundance) for complete discrimination of each individual PTC necessary (right graph side). Remmele scores of NTRK1 immunohistochemistry results are numerical. Due to the similarity of the numerical Remmele scores calculated for each of the 177 PTCs, fewer symbols appear on the right side of the graph than on the left.

thyroid cancer is attributable to radiation exposure, in particular for each individual. Due to epidemiological reasons (improved risk assessment due to radiation-specific bioindicator), forensic purposes and potential compensation claims this would be desirable. Radiation-associated PTC are typically detected during childhood or adolescence. Sporadic PTC, in contrast, are detected at higher age. However, an overlapping age range regarding the occurrence of PTC was found in our groups (Table I, Fig. 4). This overlap (15.4\% of sporadic PTC) underlines the need for the search of an individual biological parameter to elucidate individual PTC etiology. We combined 2D-gel electrophoresis and MALDI-TOF for screening of proteins with increased protein abundance in radiation-associated PTC. Twenty proteins from agarose gels of 10 patients respectively were selected as potential candidates and immunohistochemistry was performed on all biopsies. By introducing immunohistochemistry six proteins, namely matrix metalloproteinases (MMP-1, MMP-9 and MMP-13), cathepsins (Cathepsin-W and Cathepsin-X) and NTRK1, made it possible to completely discriminate the groups (Table III, Fig. 4).

MMPs and cathepsins belong to the group of proteases and lytical enzymes that are involved in the degradation of extracellular matrix components and the basement membrane. Increased MMP abundance was already shown in established PTC cell lines, in contrast to barely or non-detectable levels in normal thyrocytes or benign lesions $(15,16)$. In a previous study performed on the same PTC groups but focusing on gene expression analysis we selected MMP-1 as a candidate gene. The increased MMP-1 gene expression detected in radiation-associated PTC finally allowed a complete separation of radiation-associated from sporadic PTC using quantitative RT-PCR (13). These findings on the gene expression level were confirmed by another group (17) and provide some evidence for search on protein markers to discriminate PTC according to their etiology. It is worth noting that, due to the shown significance of altered MMP-1 gene expression for discriminating radiation-associated from sporadic PTC in previous work, we selected MMP-1 to check the protein abundance in this study. Again, we herein showed the significance of MMP-1 for discrimination purposes even on the protein level which supports our immunohistochemistry results.

Increased protein abundance of other MMPs in PTC has already been cited by others. For instance, MMP-9 identified as a critical factor in basement membrane degradation, was expressed in the majority of PTCs, and at a lower level in normal thyrocytes (18). Expression level of MMP-9 was shown as being significantly higher in patients with lymph node metastasis or intrathyroidal invasion (19). MMP-13 is known to be expressed on RNA level in thyroid tumor cell lines in contrast to normal thyrocytes (15). In squamous cell carcinomas and chondrosarcomas the expression of MMP-13 has been linked to a more aggressive and invasive tumor type (18), also characteristics typical for radiation-associated PTC.

Cathepsins $\mathrm{W}$ and $\mathrm{X}$ belong to the family of cysteine proteases and play a role in protein processing and participation in MHC II mediated antigen expression. In tumor tissues, Cathepsins are involved in the degradation of the extracellular matrix together with other proteases such as 
MMPs, thus enabling cancer growth, invasion and metastasis. As for MMPs, an upregulation for Cathepsin B and L has been shown in many tumors (21).

Our own observation of upregulated Cathepsin X and W (combined with MMPs) in post-Chernobyl PTC is in accordance with the observation that radiation-associated PTCs seem to be more aggressive than sporadic PTCs. This in particular holds true for radiation-associated PTC with short latency (22). The mean latency of the tumors investigated in our study (6.8 years) was comparable to the latency of post-Chernobyl PTC [6 and 5.7 years, respectively (22)] with already reported greater extent of intra- and extrathyroidal invasion.

NTRK1 is a tyrosine kinase receptor involved in the regulation of growth, differentiation and programmed cell death in the peripheral and central nervous system (23). The NTRK1 proto-oncogene encodes for a transmembrane receptor with tyrosine kinase (TK) activity and high affinity to the nerve growth factor (24). The oncogenic transformation of NTRK1 results from a rearrangement of the TK portion of the NTRK1 gene to the 5 ' end of several activating genes mostly belonging to the same chromosome 1 (25). Sporadic thyroid carcinomas show NTRK1 rearrangement frequency between $0-10.9 \%$ (26). A comparable frequency of 7.4\% NTRK1 rearrangements was published for radiationassociated PTCs in a group of 81 PTC from Belarus (26). The NTRK1 rearrangement status in our study was unknown. Nevertheless, the antibody used for immunohistochemistry in our study recognized the extracellular domain (20-355 aa) of the NTRK1 receptor. This domain is not involved in any known NTRK1 rearrangement. Therefore, the increased NTRK1 protein abundance observed in radiation-associated PTCs in our study (Fig. 2) indicates a rearrangementindependent role of this receptor in radiation-induced PTC.

The groups examined revealed significant age differences (Table I) which contributed to our results (Table III). However, discrimination among groups could be performed with and without considering age at operation and gender. This might be indicative of age representing a significant factor for partially explaining our results. Overlapping age ranges among both groups indicate the need for introducing other biological parameters for discrimination purposes as already discussed.

Another potential confounder could be iodine deficiency. It was present in the area where Belarusians lived and absent in the area from which the control group originated. Nowadays it is widely accepted that iodine deficiency supports the induction of a follicular histology type of thyroid cancer, but not the incidence of a papillary type (27-29).

For easy to handle routine histological examinations commercially available NTRK1 detecting antibodies (for diagnostic use) are not available, but for the other five proteins they are.

In conclusion, on 177 PTCs we showed complete discrimination of radiation-associated from sporadic PTC with a minimum of 2 proteins labeled on histological slides utilizing routinely used antibodies. Nevertheless, the limited number of histologies examined makes further examinations necessary in order to determine whether these findings are applicable as a diagnostic tool for identifying radiationassociated PTC.

\section{Acknowledgements}

This study was financed by the Ministry of Defence, Germany (M/SAB1/4/A011). Special thanks to the Proteome Center Rostock, Germany, the ECHO-Lab of the Department of General Surgery, Martin-Luther-University HalleWittenberg, Germany and to The National Academy of Sciences of Belarus for their cooperation.

\section{References}

1. Collins BJ, Schneider AB, Prinz RA and Xu X: Low frequency of BRAF mutations in adult patients with papillary thyroid cancers following childhood radiation exposure. Thyroid 16: 61-66, 2006.

2. Blackburn DJ, Michel LA, Rosiere A, Trigaux JP and Donckier JE: Occurrence of thyroid papillary carcinoma in young patients. A Chernobyl connection? J Pediatr Endocrinol Metab 14: 503-506, 2001.

3. Schlumberger M, Cailleux AF, Suarez HG and de Vathaire F: Irradiation and second cancers. The thyroid as a case in point. $\mathrm{C}$ R Acad Sci III 322: 205-213, 1999.

4. Wiersinga WM: Thyroid cancer in children and adolescentsconsequences in later life. J Pediatr Endocrinol Metab (Suppl. 5) 14: S1289-S1298, 2001.

5. Pacini T, Vorontsova E, Molinaro E, et al: Thyroid consequences of the Chernobyl nuclear accident. Acta Paediatr (Suppl) 88: 23-27, 1999.

6. Shirahige Y, Ito M, Ashizawa K, et al: Childhood thyroid cancer: comparison of Japan and Belarus. Endocr J 45: 203-209, 1998.

7. Leenhardt L, Grosclaude P and Cherie-Challine L: Increased incidence of thyroid carcinoma in France: a true epidemic or thyroid nodule management effects? Report from the French Thyroid Cancer Committee. Thyroid 14: 1056-1060, 2004.

8. Cotterill SJ, Pearce MS and Parker L: Thyroid cancer in children and young adults in the North of England. Is increasing incidence related to the Chernobyl accident? Eur J Cancer 37: 1020-1026, 2001.

9. Abelin T, Averkin JI, Egger M, et al: Thyroid cancer in Belarus post-Chernobyl: improved detection or increased incidence? Soz Praventivmed 39: 189-197, 1994.

10. Jaworowski Z: Czernobyl accident: regional and global impacts. Environ Int 14: 69-73, 1998.

11. Ashok RS: TNM Classification of Thyroid Carcinoma. World J Surg 31: 879-887, 2007.

12. Remmele W, Hildebrand U, Hienz H, et al: Comparative histological, histochemical, immunohistochemical and biochemical studies on oestrogen receptors, lectin receptors, and Barr bodies in human breast cancer. Virchows Arch 409: 127-147, 1986.

13. Port M, Boltze C, Wang Y, Röper B, Meineke V and Abend M: A radiation-induced gene signature distinguishes post-chernobyl from sporadic papillary thyroid cancers. Radiat Res 168: 639-649, 2007.

14. Tseleni-Balafouta S, Gakiopoulou H, Fanourakis G, Voutsinas G, Balafoutas D and Patsouris E: Tenascin-C protein expression and mRNA splice variants in thyroid carcinoma. Exp Mol Pathol 80: 177-182, 2006.

15. Baldini E, Toller M, Graziano FM, et al: Expression of matrix metalloproteinases and their specific inhibitors in normal and different human thyroid tumor cell lines. Thyroid 14: 881-888, 2004.

16. Korem S, Resnick MB and Kraiem Z: Similar and divergent patterns in the regulation of matrix metalloproteinases-1 (MMP-1) and tissue inhibitor of MMP-1 gene expression in benign and malignant human thyroid cells. J Clin Endocrinol Metab 84: 3322-3327, 1999.

17. Detour V, Delys L, Libert F, et al: Genome-wide gene expression profiling suggests distinct radiation susceptibilities in sporadic and post-Chernobyl papillary thyroid cancers. Br J Cancer 97: 818-825, 2007.

18. Brinckerhoff CE, Rutter JL and Benbow U: Interstitial collagenases as markers of tumor progression. Clin Cancer Res 6: 4823-4830, 2000.

19. Maeta H, Ohgi S and Terada T: Protein expression of matrix metalloproteinases 2 and 9 and tissue inhibitors of metalloproteinase 1 and 2 in papillary thyroid carcinomas. Virchows Arch 438: 121-128, 2001. 
20. Berdowska I: Cysteine proteases as disease markers. Clin Chim Acta 342: 41-69, 2004.

21. Williams ED, Abrosimov A, Bogdanova T, et al: Thyroid carcinoma after Chernobyl latent period, morphology and aggressiveness. Br J Cancer 90: 2219-2224, 2004.

22. Teng KK and Hempstead BL: Neurotrophins and their receptors: signaling trios in complex biological systems. Cell Mol Life Sci 61: 35-48, 2004

23. Klein R, Jing SQ, Naduri V, O'Rourke E and Barbacid M: The trk-proto-oncogene encodes a receptor for nerve growth factor. Cell 65: 189-197, 1991.

24. Pierotti MA, Bongarzone I, Borrello MG, Greco A, Pilotti S and Sozzi G: Cytogenetics and molecular genetics of carcinomas arising from thyroid epithelial follicular cells. Genes Chromosomes Cancer 16: 1-14, 1996.
25. Beimfohr C, Klugbauer S, Demidchik EP, Lengfelder E and Rabes HM: NTRK1 rearrangement in papillary thyroid carcinomas of children after the Chernobyl reactor accident. Int J Cancer 80: 842-847, 1999.

26. Hall P: Radiation-induced thyroid cancer. Med Oncol Tumor Pharmacother 4: 183-189, 1992

27. Williams ED, Pacini $F$ and Pinchera A: Thyroid cancer following Czernobyl. J Endocrinol Invest 18: 144-146, 1995.

28. Boltze C, Brabant G, Dralle H, Gerlach R, Roessner A and Hoang-Vu C: Radiation-induced thyroid carcinogenesis as function of time and dietary iodine supply-an in vivo model of tumorigenesis in the rat. Endocrinology 143: 2584-2592, 2002. 